\title{
Odontoid fractures: impact of age and comorbidities on surgical decision making
}

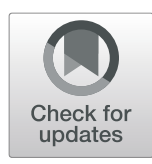

Syed Ali Mujtaba Rizvi1,2, Eirik Helseth 1,2, Pål Rønning², Jalal Mirzamohammadi², Marianne Efskind Harr², Tor Brommeland², Mads Aarhus², Christina Teisner Høstmælingen², Håvard Ølstørn², Pål Nicolay Fougner Rydning ${ }^{2}$, Magnus Mejæender-Evjensvold ${ }^{3}$, Nils Christian Utheim² and Hege Linnerud ${ }^{2 *}$ (i)

\begin{abstract}
Background: Surgical fixation is recommended for type II and III odontoid fractures (OFx) with major translation of the odontoid fragment, regardless of the patient's age, and for all type II OFx in patients aged $\geq 50$ years. The level of compliance with this recommendation is unknown, and our hypothesis is that open surgical fixation is less frequently performed than recommended. We suspect that this discrepancy might be due to the older age and comorbidities among patients with OFX.
\end{abstract}

Methods: We present a prospective observational cohort study of all patients in the southeastern Norwegian population (3.0 million) diagnosed with a traumatic OFx in the period from 2015 to 2018.

Results: Three hundred thirty-six patients with an OFx were diagnosed, resulting in an overall incidence of 2.8/ 100000 persons/year. The median age of the patients was 80 years, and $45 \%$ were females. According to the Anderson and D'Alonzo classification, the OFx were type II in 199 patients (59\%) and type III in 137 patients (41\%). The primary fracture treatment was rigid collar alone in $79 \%$ of patients and open surgical fixation in $21 \%$. In the multivariate analysis, the following parameters were significantly associated with surgery as the primary treatment: independent living, less serious comorbidities prior to the injury, type II OFx and major sagittal translation of the odontoid fragment. Conversion from external immobilization alone to subsequent open surgical fixation was performed in $10 \%$ of patients. Significant differences the in conversion rate were not observed between patients with type II and III fractures. The level of compliance with the treatment recommendations for OFx was low. The main deviation was the underuse of primary surgical fixation for type II OFx. The most common reasons listed for choosing primary external immobilization instead of primary surgical fixation were an older age and comorbidities.

Conclusion: Major comorbidities and an older age appear to be significant factors contributing to physicians' decision to refrain from the surgical fixation of OFx. Hence, comorbidities and age should be considered for inclusion in the decision tree for the choice of treatment for OFx in future guidelines.

Keywords: Spinal fractures/epidemiology, Odontoid process/injury, Age factors, Comorbidity, Risk factors, Spinal fractures/surgery, Guideline adherence

\footnotetext{
* Correspondence: Uxegfr@ous-hf.no

${ }^{2}$ Department of Neurosurgery, Oslo University Hospital, Mailbox 4956, 0424

Oslo, Norway

Full list of author information is available at the end of the article
}

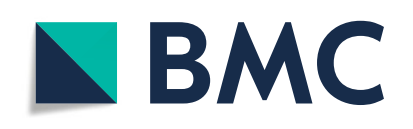

(- The Author(s). 2020 Open Access This article is licensed under a Creative Commons Attribution 4.0 International License, which permits use, sharing, adaptation, distribution and reproduction in any medium or format, as long as you give appropriate credit to the original author(s) and the source, provide a link to the Creative Commons licence, and indicate if changes were made. The images or other third party material in this article are included in the article's Creative Commons licence, unless indicated otherwise in a credit line to the material. If material is not included in the article's Creative Commons licence and your intended use is not permitted by statutory regulation or exceeds the permitted use, you will need to obtain permission directly from the copyright holder. To view a copy of this licence, visit http://creativecommons.org/licenses/by/4.0/. The Creative Commons Public Domain Dedication waiver (http://creativecommons.org/publicdomain/zero/1.0/) applies to the data made available in this article, unless otherwise stated in a credit line to the data. 


\section{Background}

The incidence of traumatic cervical spine fractures (CS$\mathrm{fx}$ ) in the Norwegian population is $15 / 100,000$ /year [1]. Twenty percent of these fractures are odontoid fractures (OFx) of cervical vertebra 2 (C2) [2]. The incidence of this injury increases with age, making OFx the most common CS-fx in the elderly population [2-4]. OFx are subdivided into types I, II and III according to the classification proposed by Anderson and D'Alonzo [5]. Type I fractures are very rare and do not require stabilization, while type II and III fractures are common and considered unstable.

A minor proportion of patients with OFx die immediately at the scene of the accident due to severe fracture dislocation with subsequent injury to the upper spinal cord, causing tetraplegia and respiratory arrest [6-8]. However, the majority of patients present with an OFx after trauma with various degrees of neck pain. When left untreated, these patients are at risk of fracture dislocation with secondary spinal cord injury (SCI) or persistent and severe neck pain due to chronic instability/ pseudarthrosis. The aims of treatment are to preserve neurological function, provide pain relief and establish bony fusion. A consensus for the management of OFx is currently lacking, and the choice of treatment has mainly been guided by the fracture type (II or III), magnitude and direction of displacement of the OFx fragment, patient age and the knowledge of variations in bony fusion rates after the use of different treatment options [9-11].

Several publications recommend primary surgical fixation for type II and III OFx with major translation of the odontoid fragment, regardless of the patient's age, and for all type II OFx in patients aged $\geq 50$ years $[4,11-14]$. For the remaining patients, primary external immobilization is advised. These previous recommendations do not consider the effects of an older age and comorbidities of the patients, nor the possibility of a stable fibrous union as a satisfactory result of treatment. Recent reports have questioned these previous recommendations and advocate that patient age and comorbidities should be included in future treatment algorithms and that a stable fibrous union should be regarded as an acceptable outcome [15-18].

The recommendation of surgery for all patients aged $\geq 50$ years with OFx type II is a subject of debate, since most of these fractures occur in the elderly with major comorbidities and increased risks of surgical morbidity and mortality $[16,19,20]$. The bony fusion rate of OFx type II in patients aged $\geq 50$ years is higher after surgical fixation than after external immobilization in a rigid collar or Halo-vest for 12 weeks [11, 13, 21]. However, according to recent reports, many patients will exhibit a stable fibrous union of the OFx after 12 weeks of external mobilization, despite the lack of bony fusion [15-18]. This fibrous union is defined by a lack of pathological movement of the odontoid fragment upon dynamic flexion and extension studies performed under fluoroscopic guidance, despite the absence of radiological bony fusion.

The level of compliance with the aforementioned treatment recommendations in our department is unknown. In the current study, we present updated epidemiological data on OFx in a defined population of 3.0 million people. The effects of the fracture type, displacement of the odontoid fragment, patient age and comorbidities on the rate of open surgical fixation are discussed. Our hypothesis is that open surgical fixation is less frequently performed than recommended, and we suspect that this discrepancy might be due to the older age and comorbidities observed in patients with OFx.

\section{Methods}

Oslo University Hospital (OUH) is a level 1 trauma centre located in Oslo, Norway and the only major trauma care facility in the Southeastern Norwegian Regional Health Authority (Norwegian: Helse Sør-Øst RHF). OUH is the only hospital in this region with neurosurgical service. In 2017, the southeastern region of Norway had 2.95 million inhabitants with the following age distribution: 1913884 aged $0-49$ years, 381,157 aged $50-59$ years, 318,407 aged $60-69$ years, 215,141 aged 70-79 years, 97,333 aged $80-89$ years and 24,623 aged $>90$ years [22]. OUH performs $>95 \%$ of the trauma-related neurosurgical procedures in this population, including all surgeries for cervical spine injury. Twenty hospitals within our region with general and/or orthopaedic surgeons and radiological services refer patients with head and cervical spine injuries to OUH. The patients are either admitted to OUH for treatment or are managed locally when the neurosurgical team at OUH has decided that conservative treatment is indicated. We use a rigid collar for external immobilization. Treatment with a Halo-vest was discontinued in our region several years ago.

This study employed a prospective observational cohort design and examined all patients in the southeastern Norwegian population diagnosed with a traumatic OFx in the period from 2015 to 2018. The data were retrieved from our quality control database for traumatic CS- $\mathrm{fx}$ in southeastern Norway. In this database, all patients with CS-fx ( $\mathrm{C} 0 / \mathrm{C} 1$ to $\mathrm{C} 7 / \mathrm{Th} 1)$ who were diagnosed using cervical $\mathrm{CT}$ within our region are prospectively registered. Only patients with an 11-digit unique Norwegian social security number who were living within the region were included. The database was approved by the OUH - Data Protection Officer (PVO) (approval no 2014/12304), generated in Medinsight, and run by the Department of Neurosurgery. The present study, which is based on data extracted from this quality 
database, was approved by OUH-PVO, and consent was waived by our Institutional Review Board (approval no 18/02167).

For this study, the following data were extracted from the database: date of injury, injury mechanism, gender, age at the time of injury, living status at the time of injury (home - care for self, home - with assistance, or institutionalized), pre-injury American Society of Anesthesiologists (ASA) score [23], type of OFx (types IIII) according to the classifications proposed by Anderson and D'Alonzo [5] and Grauer et al. [24], sagittal displacement of the odontoid fragment (direction and magnitude), presence of other cervical fractures (yes/no), multi-trauma (yes/no), Head Injury Severity Score (HISS) [25], presence of a concomitant thoracolumbar fracture (yes/no), presence of a SCI (yes/no), treatment (external immobilization with rigid collar alone or open surgical fixation), compliance with the previous treatment recommendations for OFx with respect to surgical fixation (yes/no) and reason for non-compliance based on a chart review.

The pre-injury ASA score was defined as follows: 1. a normal healthy patient, 2 . a patient with a mild systemic disease, 3 . a patient with a severe systemic disease, 4 . a patient with severe systemic disease that is a constant threat to life, and 5. a moribund patient who is not expected to survive without surgery.

Previous treatment recommendations for OFx include primary surgical fixation for type II and III fractures with major displacement of the odontoid fragment, regardless of the patient's age, and for all type II fractures in patients aged $\geq 50$ years. For the remaining patients with OFx, primary external immobilization is recommended.

Major sagittal displacement of the odontoid fragment was defined as a translation $\geq 5 \mathrm{~mm}$ anterior or $\geq 3 \mathrm{~mm}$ posterior [13].

Reasons for non-compliance were categorized as follows: surgery was not performed due to an older age and/or comorbidities, the diagnosis was delayed $>12$ weeks, or the presence of a non-survivable injury.

Multi-trauma was defined as a simultaneous traumatic brain injury (mild, moderate or severe), and/or radiology-proven (X-ray, CT or ultrasound) injury in one or more of the following regions: face, thoracolumbar spine, thorax, abdomen, pelvic or extremities. Skin injuries were not registered.

\section{Statistical analysis}

Data were summarized as frequencies and means or medians, according to the distribution of the variables. Pearson's chi-squared test was used to compare differences in frequencies between groups. The KruskalWallis test was used to compare the distributions between multiple groups. A Poisson model was used to investigate the effect of age on the incidence of injury in the different age groups. Both uni- and multivariate logistic regression models were fitted for binary dependent variables. The $\mathrm{R}$ package v3.6 was used for statistical analyses. $P$-values less than 0.05 were considered significant.

\section{Results}

In our defined population of 3.0 million people in southeastern Norway, 336 patients with an OFx were prospectively registered during a 4 year period from 2015 to 2018, resulting in an overall OFx incidence of 2.8/ 100000 persons/year. However, the incidence in the elderly was considerably higher (Fig. 1a).

Patient characteristics and injury descriptions are presented in Table 1 . The median patient age was 80 years (range 6-100 years), and 150/336 (44.6\%) were females. The number of OFx increased with age (incidence rate ratio 2.5 for 10 year increments, 95\% CI 2.3-2.9, $p<$ 0.001). A male predominance was observed in younger patients, while a gradual shift to a female predominance was observed among older patients (Fig. 1b). The OFx were classified as type II fractures in 199 patients (59.2\%) and type III fractures in 137 patients (40.8\%). Type II OFx were more frequent than type III OFx $(p<$ 0.001). Major sagittal translation was observed in $48 / 196$ (24.5\%) of patients with a type II OFx and 21/137 (15.3\%) of patients with a type III OFx. Translation data were missing for 3 patients (Table 2).

Pre-injury major comorbidities (ASA $\geq 3$ ) were present in $213(63.7 \%)$ of the patients, and $115(34.3 \%)$ required assistance with ADL (Table 1). An increasing age was significantly associated with both a greater number of comorbidities $(p<0.001)$ and a need for assistance with ADL $(p<0.001)$. Furthermore, a significant association was observed between a high ASA score and the need for assistance with ADL $(p=0.02)$.

The most common trauma mechanism was falls (85.7\%), followed by motorized vehicle accidents $(4.8 \%)$ and bicycle accidents (4.5\%) (Table 1). The fraction of fall-related injuries increased significantly with 10 year increments in age $(1.71,95 \%$ CI $(1.42-2.08), \mathrm{p}<0.001)$, from $53 \%$ in the group aged $<50$ years to $95 \%$ in patients aged $>80$ years. Multi-trauma was registered in $142 \mathrm{pa}$ tients $(42.6 \%)$. SCI due to OFx was present in 13 patients (3.9\%).

The primary fracture treatment was a rigid collar alone in 266 patients $(79.2 \%)$ and open surgical fixation followed by external immobilization in 70 patients (20.8\%). In the univariate analysis, the following parameters were significantly associated with the use of surgery as the primary treatment: male sex, young age, independent living, pre-injury ASA score of 1-2, type II OFx and major sagittal translation of the odontoid fragment 

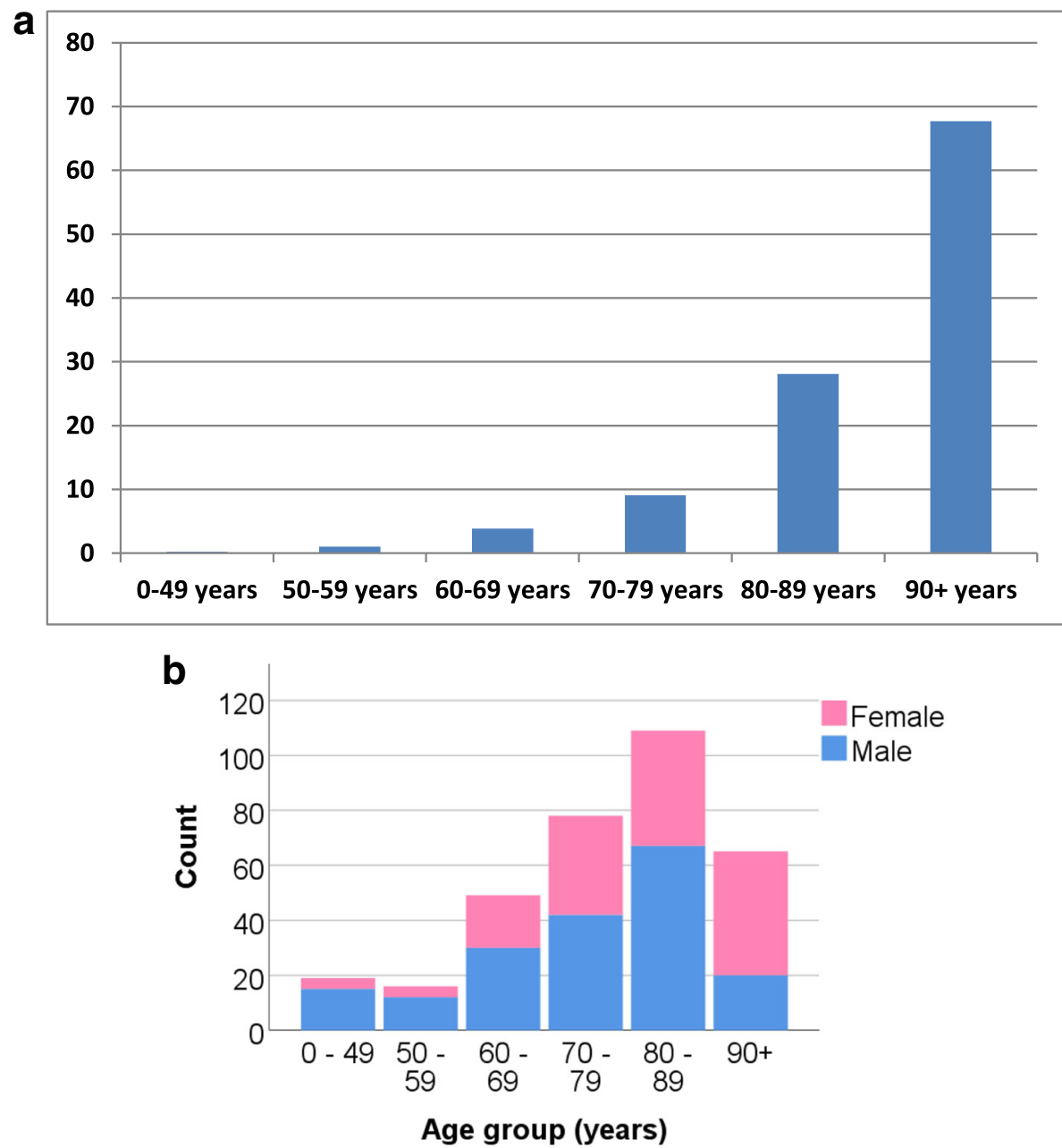

Fig. 1 a: Age-adjusted incidence rates (x/100000 persons/year). b: Number of odontoid fractures in groups stratified according to age and gender

(Table 2). In the multivariate analysis, the following parameters remained significantly associated with the use of surgery as the primary treatment: independent living, pre-injury ASA score of 1-2, type II OFx and major sagittal translation of the odontoid fragment (Table 2). Male sex and age were not associated with the use of surgery as the primary treatment in the multivariate analysis.

Conversion from external immobilization alone to subsequent open surgical fixation was performed in 26/ 266 patients $(9.8 \%)$ due to increased dislocation, severe neck pain hindering mobilization or pseudarthrosis. Treatment conversion was performed in 15/135 (11.1\%) of patients with a type II OFx compared with 11/131 (8.4\%) of patients with a type III OFx. This difference in conversion between patients with type II and III fractures was insignificant ( $p=0.618)$.

Our compliance with the aforementioned previous treatment recommendations for $\mathrm{OFx}$ is presented in
Table 3 and appears to be low. The three largest patient categories in our series were patients aged $\geq 50$ years with a type II fx (category $1, n=184$ ), patients with a type III fx without major translation (category 2, $n=116$ ), and patients with a type III $\mathrm{fx}$ with major translation (category 3 , $n=21$ ). For patients in category 1 , the recommended treatment is primary surgical fixation, but this procedure was only performed in 33\% of patients. For patients in category 2 , the recommended treatment is primary external immobilization, which was performed in $98 \%$ of patients. For patients in category 3 , the recommended treatment is primary surgical fixation, but it was only performed in $19 \%$ of patients. The main deviation from the previous guidelines was the underuse of primary surgical fixation. Based on chart reviews, the reasons listed for choosing primary external immobilization instead of primary surgical fixation included a combination of age and comorbidities in 122 patients, lethal injury in 8 patients and delayed diagnosis in 8 patients (Table 4). 
Table 1 Patient characteristics

\begin{tabular}{|c|c|c|}
\hline & & $336(100 \%)$ \\
\hline \multirow[t]{2}{*}{ Sex } & Male & $186(55.4)$ \\
\hline & Female & $150(44.6)$ \\
\hline \multirow[t]{6}{*}{ Age group (years) } & $0-49$ & $19(5.7)$ \\
\hline & $50-59$ & $16(4.8)$ \\
\hline & $60-69$ & 49 (14.6) \\
\hline & 70-79 & $78(23.2)$ \\
\hline & $80-89$ & $109(32.4)$ \\
\hline & $90+$ & $65(19.3)$ \\
\hline \multirow[t]{5}{*}{ Pre-injury ASA score ${ }^{a}$} & ASA score of 1 & $33(9.8)$ \\
\hline & ASA score of 2 & $89(26.5)$ \\
\hline & ASA score of 3 & $187(55.7)$ \\
\hline & ASA score of 4 & $26(7.7)$ \\
\hline & Not available & $1(0.3)$ \\
\hline \multirow[t]{4}{*}{ Dependence in daily life } & Home - independent & $220(65.5)$ \\
\hline & Home - with assistance & $62(18.5)$ \\
\hline & Institution & $53(15.8)$ \\
\hline & Not available & $1(0.3)$ \\
\hline \multirow[t]{5}{*}{ Injury mechanism } & Fall & $288(85.7)$ \\
\hline & Motorized vehicle (MV) & $16(4.8)$ \\
\hline & Bicycle & $15(4.5)$ \\
\hline & Pedestrian hit by MV or bicycle & $5(1.4)$ \\
\hline & Other & $12(3.6)$ \\
\hline \multirow[t]{2}{*}{ Odontoid fracture } & Type ॥ & $199(59.2)$ \\
\hline & Type III & $137(40.8)$ \\
\hline \multirow[t]{4}{*}{ Other spine fractures } & $\mathrm{C} 1$ & $64(19.1)$ \\
\hline & CO (occipital condyle) & $9(2.7)$ \\
\hline & C3 - Th1 & $27(8.1)$ \\
\hline & Thoracolumbar & $30(8.9)$ \\
\hline \multirow[t]{3}{*}{ Spinal cord injury (SCl) } & Odontoid fx & $13(3.9)$ \\
\hline & Other cervical fx & $1(0.3)$ \\
\hline & Thoracolumbar fx & $2(0.6)$ \\
\hline \multirow[t]{10}{*}{ Multi-trauma } & Yes & $143(42.6)$ \\
\hline & $\left.\mathrm{TB}\right|^{\mathrm{b}}-$ Mild & $91(27.1)$ \\
\hline & TBI - Moderate & $11(3.3)$ \\
\hline & TBI - Severe & $9(2.7)$ \\
\hline & Face & $29(8.6)$ \\
\hline & Thoracolumbar fx & $30(8.9)$ \\
\hline & Thorax & $29(8.6)$ \\
\hline & Abdomen & $5(1.5)$ \\
\hline & Pelvic & $5(1.5)$ \\
\hline & Extremity & $27(8.0)$ \\
\hline
\end{tabular}

${ }^{\mathrm{a} A S A}$ American Society of Anesthesiologists

${ }^{\mathrm{b}} T B /$ Traumatic Brain Injury

\section{Discussion}

As shown in the present study, the estimated incidence of traumatic OFx in the southeastern Norwegian population is $2.8 / 100000$ persons/year. The fractures mainly occurred in elderly patients with significant comorbidities. The primary treatment was external immobilization alone in $79 \%$ and open surgical fixation in $21 \%$. In the multivariate analysis, independent living, pre-injury ASA scores of 1-2, type II OFx and major sagittal translation of the odontoid fragment were significantly associated with the use of surgery as the primary treatment. The low rate of surgery is intriguing, since previous reports have documented that the bony fusion rate is higher after surgical fixation than after external immobilization alone.

\section{Epidemiology}

A specific International Classification of Disease (ICD) code is not available for OFx [26]. This fracture shares the ICD-10 code S12.1 with all other forms of C2 fractures. This finding is important, since the majority of previous epidemiological studies report the incidence of all types of $\mathrm{C} 2$ fractures and not odontoid fractures exclusively, as they are based on the extraction of ICD codes from registries. A Swedish nationwide registry study conducted from 1997 to 2014 reported that the incidence of C2 fractures increased from 3/100000 persons/year in 1997 to 6/100000 persons/year in 2014 [27]. These numbers are not directly comparable to our results, as the $\mathrm{C} 2$ fractures were not sub-typed. Another Swedish regional study estimated the incidence of OFx in the period from 2002 to 2014 to be $3 / 100000$ persons/year [3]. Based on a United States nationwide registry on hospitalized patients for the period from 2000 to 2010, the incidence of C2 fractures is approximately $1 /$ 100000 persons/year [28]. A reasonable conclusion would be that the Norwegian incidence of OFx of 2.8/ 100000 persons/year is within the range of previously published results, although these studies provide a limited basis for comparison.

The median age of our patients was 80 years, and the frequency of OFx increased with increasing age in our study population. This finding is consistent with numerous other reports $[3,27-30]$. The reported increase in incidence of OFx and C2 fractures in the geriatric population during the few last decades cannot be explained simply by an extended life expectancy. One can argue that the use of CT instead of plain X-ray as the primary diagnostic tool probably explains phenomenon portion of this increase [27-30].

A slight male predominance (55\%) was observed in our patients with OFx. However, this predominance disappeared with increasing age, and among patients aged $>90$ years, the number of women with an $\mathrm{OFx}$ 
Table 2 Uni- and multivariate analyses of variables potentially associated with the use of surgery as the primary treatment

\begin{tabular}{llllll}
\hline Variable & & $\begin{array}{l}\text { Primary conservative } \\
\text { treatment } \\
\mathbf{N}(\%)\end{array}$ & $\begin{array}{l}\text { Primary } \\
\text { surgery } \\
\mathbf{N}(\%)\end{array}$ & OR $^{\text {a }}$ (univariate) & OR (multivariate) \\
\hline Sex & Female & $129(86.0)$ & $21(14.0)$ & - & - \\
& Male & $137(73.7)$ & $49(26.3)$ & $2.20(1.26-3.93, p=0.006)$ & $1.44(0.71-2.95, p=0.311)$ \\
Age & Mean $\left(\mathrm{SD}^{\mathrm{b}}\right)$ & $78.3(16.1)$ & $71.0(11.4)$ & $0.97(0.96-0.99, p=0.001)$ & $1.00(0.98-1.02, p=0.904)$ \\
Functional status & Dependent & $110(95.7)$ & $5(4.3)$ & - & - \\
& Independent & $155(70.5)$ & $65(29.5)$ & $9.23(3.95-27.01, p<0.001)$ & $5.86(2.15-19.08, p=0.001)$ \\
ASAc score & ASA score of 1-2 & $77(63.6)$ & $44(36.4)$ & - & - \\
& ASA score of 3-4 & $189(87.9)$ & $26(12.1)$ & $0.24(0.14-0.42, p<0.001)$ & $0.30(0.13-0.65, p=0.003)$ \\
Odontoid fracture type & Type II & $136(68.0)$ & $64(32.0)$ & - & - \\
& Type III & $130(95.6)$ & $6(4.4)$ & $0.10(0.04-0.22, p<0.001)$ & $0.08(0.03-0.19, p<0.001)$ \\
Odontoid translation & None-Mild & $225(85.2)$ & $39(14.8)$ & - & -
\end{tabular}

${ }^{\mathrm{a} O R}$ Odds ratio

${ }^{\mathrm{b}} S D$ Standard deviation

${ }^{\mathrm{C}}$ ASA American Society of Anesthesiologists

${ }^{\mathrm{d}}$ Major odontoid translation $-\geq 5 \mathrm{~mm}$ anterior or $\geq 3 \mathrm{~mm}$ posterior

outnumbered men. This result corresponds to the increasing proportion of women in the older age groups of the population [22]. Similar findings have also been reported by other groups [27, 31].

An increasing age was significantly associated with a greater number of comorbidities, as measured using the pre-injury ASA score, and the need for assistance with ADL. Previous studies have also documented increased numbers of comorbidities among geriatric patients sustaining OFx [32-37]. Age and comorbidities are of course linked to some extent, but we postulate that they act as separate risk factors for OFx. The risk of healthy older people to suffer an OFx is probably lower than older people with comorbidities. Illness often leads to inactivity or a neurological disability, which pre-disposes an individual to osteoporosis and an increased risk of unintended falls [38]. A higher burden of disease will lead to the use of medications in many cases, and several classes of medications are associated with an increased risk of falls in the elderly [39]. The WHO has defined risk factors for falls, including polypharmacy treatment, comorbidities, an age $>80$ years, and impaired cognition and vision [40]. The presence of a medical comorbidity may also predispose patients to an increased risk of

Table 3 Rate of compliance with published treatment recommendations for odontoid fractures [4, 11-14]. Green indicates compliance and red indicates non-compliance. Translation data were missing for 3 patients who were treated conservatively

\begin{tabular}{|l|c|c|c|}
\hline & Surgery & Conservative & $\%$ Compliance \\
\hline $\begin{array}{l}\text { Type II fx in patients aged }<50 \text { y without } \\
\text { major translation }\end{array}$ & $1 / 9$ & $8 / 9$ & $89 \%$ \\
\hline $\begin{array}{l}\text { Type II fx in patients aged <50 y with major } \\
\text { translation }\end{array}$ & $2 / 3$ & $1 / 3$ & $67 \%$ \\
\hline Type II fx in patients aged $\geq 50$ y & $61 / 184$ & $123 / 184$ & $33 \%$ \\
\hline & & & \\
\hline Type III fx without major translation & $2 / 116$ & $114 / 116$ & $98 \%$ \\
\hline Type III fx with major translation & $4 / 21$ & $17 / 21$ & $19 \%$ \\
\hline
\end{tabular}


Table 4 Rate of non-compliance with published treatment recommendations for odontoid fractures, and reasons why primary external immobilization was chosen instead of primary surgical fixation [4, 11-14]

\begin{tabular}{lll}
\hline & Reason for non-compliance & N (\%) \\
\hline Compliant & & $195(58.0)$ \\
Non-compliant & Age/comorbidities & $122(36.3)$ \\
& Lethal injury & $8(2.4)$ \\
& Delayed diagnosis & $8(2.4)$ \\
Missing data & & $3(0.9)$ \\
\hline
\end{tabular}

complications in the setting of fracture care, such as thromboembolic disease, cardiac events and infections. The in-hospital mortality rates in this patient group, regardless of the choice of treatment, have been reported to be as high as $10-25 \%[33,35,37,41,42]$, and 1-year mortality rates are $20-50 \%[19,20,37,42,43]$. The principal causes of death are related to their comorbidities and not the injury itself for the majority of patients with OFx $[19,20]$. This high burden of disease represents a major concern in many of these patients regarding whether they will be able to tolerate general anaesthesia and open surgery.

The most common trauma mechanism among our patients was falls (85.7\%), followed by motorized vehicle accidents $(4.8 \%)$ and bicycle accidents (4.5\%) The fraction of fall-related injuries was $53 \%$ in the group aged < 50 years and $95 \%$ in patients aged $>80$ years. Several authors have identified falls as the major trauma mechanism in elderly patients suffering an OFx, particularly falls from a standing height $[15,31,42,44-46]$.

\section{Fracture morphology}

In our cohort of patients with OFx, 59\% had type II fractures and $41 \%$ had type III fractures. Interestingly, type I fractures were not observed. Our proportion of patients with type II OFx is somewhat lower than the values reported from the UK and Sweden. In a UK study, type II and type III OFx constituted 84 and $16 \%$ of the injuries, respectively [31], while a Swedish study reported $1 \%$ type I, $69 \%$ type II and $29 \%$ type III fractures [3]. All studies, including ours, used the Anderson and D'Alonzo classification with the Grauer modification.

SCI secondary to dislocation of the odontoid fragment was observed in 13 patients (3.9\%) in our series. Other researchers have reported a rate of SCI in patients with OFx or all C2 fractures ranging from 2 to $6 \%$ [27, 37, 42, 47]. The number of SCIs after OFx may be higher than reported, since a severe $\mathrm{SCI}$ at the $\mathrm{C} 2$ level may be fatal at the scene of the accident $[6-8,48]$.

\section{Treatment}

The main treatment goals for patients with OFx are to preserve the neurological function, relieve pain and establish a stable fusion. To date, no real consensus has been achieved and class I evidence for the management of these fractures is lacking $[9,11]$. Historically, "stable fusion" has been rated synonymously with bony fusion. Recent publications have proposed that age and comorbidities should be emphasized as independent variables in treatment algorithms for OFx and that a fibrous union might be a valid result of treatment in these patients [16, 33, 41, 49-52].

External immobilization is typically achieved using a Halo-vest or stiff neck collar. A meta-analysis of 12 studies (714 fractures) comparing the Halo-vest with collar immobilization identified an equivalent rate of nonunion between the treatment groups, but the number of complications more than doubled in patients treated with Halo-vests [53]. Thus, when choosing conservative treatment, a reasonable approach is to primarily use a rigid neck collar. When surgery is chosen, the evidence is in favour of performing a posterior screw fixation if the goal is bony fusion, which has historically been the definition of a successful treatment [10].

Most likely, a large proportion of elderly patients and patients with comorbidities presenting with OFx have not been included in randomized control trials (RCTs) comparing conservative and surgical treatment for $\mathrm{OFx}$ due to the high surgical risks. In non-randomized cohort studies, a high potential for selection bias exists because surgeons tend to select healthier patients for surgery. This bias in the published literature should always be considered when evaluating reported outcomes after the treatment of odontoid fractures in the geriatric population.

\section{Rate of surgery in southeastern Norway}

Despite the evidence for a superior bony fusion rate after the surgical fixation of OFx, we have suspected that the rate of surgery for these fractures in our department is low. We also postulated that the reasons for this potentially low rate of surgery were the older age and comorbidities among the patients. These hypotheses were verified in this study, as we chose surgery as the primary treatment for $21 \%$ of the total patients, and surgery was chosen more often for patients with type II OFx than type III OFx. The largest group in which we refrained from treating the patients according to previous recommendations was patients with a type II OFx aged $>50$ years. The low use of primary surgical fixation in our study was clearly associated with an older age and comorbidities. The main concern with this low rate of surgery is a potentially high rate of treatment failure after external immobilization alone. In our series, the failure 
of external immobilization alone leading to subsequent open surgical fixation occurred in $9.8 \%$ of patients. Primary external immobilization of type II OFx was not associated with a higher rate of conversion to open surgical fixation compared to type III OFx (11.1\% versus 8.4\%). A 9.8\% failure rate may be considered high. However, $90.2 \%$ of the patients selected for external immobilization were successfully treated, most of whom were high risk candidates for surgery due to age and severe comorbidities.

The high rate of clinically successful treatment with external immobilization alone, despite the expected low rate of bony fusion, indicates that stable fibrous union is an acceptable outcome.

Reported rates of surgery for OFx vary considerably, but many series present a low surgery rate (12-28\%) in elderly patients [37, 41, 42]. A few publications present a higher surgery rate, with $46-53 \%$ of patients in all age groups undergoing surgery for type II OFx and 13-19\% of patients undergoing surgery for type III OFx [3, 31]. Studies reporting on all C2 fractures in the elderly in the United States show a surgery rate of $10-16 \%[54,55]$. Because the majority of $\mathrm{C} 2$ fractures in the elderly are type II OFx, the findings imply a low surgical treatment rate in the elderly with this type of fracture.

\section{Limitations of the study}

This study only presents epidemiological data and a description of our current treatment practice for patients with OFx. Based on the results of the present study, we are unable to conclusively determine whether this low rate of surgery is acceptable or represents a suboptimal practice.

We hope to answer this important question with our large observational cohort study of $>500$ consecutive patients with OFx who were treated from 2009 to 2017. The data from the follow-up of this cohort are now being processed and we believe that the results will provide important insights into management of these fractures.

\section{Conclusions}

In southeastern Norway, $21 \%$ of patients with OFx were treated with primary open surgical fixation. Major comorbidities (ASA $\geq 3$ ) were present prior to trauma in approximately $2 / 3$ of the patients, $1 / 3$ needed assistance with ADL, and more than half of the patients were $\geq 80$ years of age.

Major comorbidities and an older age appear to be significant factors contributing to the decision to refrain from the surgical fixation of OFx. Hence, comorbidities and age should probably be considered for inclusion in the decision tree for the choice of treatment for OFx in future guidelines.

\section{Abbreviations}

CS-fx: Cervical spine fractures; OFx: Odontoid fractures; C2: Cervical vertebra 2; SCl: Spinal cord injury; OUH: Oslo University Hospital; ASA: American Society of Anesthesiologist; HISS: Head Injury Severity Scale; ADL: Activities of daily living; ICD: International Classification of Disease

\section{Acknowledgments}

We would like to thank the colleagues at Oslo University Hospital for help with registration in the quality control database for traumatic CS-fx in southeastern Norway.

\section{Authors' contributions}

Research design: SAMR, EH, HL. Acquisition of data: SAMR, EH, HL, JM, MEH, TB, PNFR, MA, CTH, HØ, MM-E, NCU. Interpretation of data: SAMR, EH, HL, PR. All authors revised and approved the final submitted manuscript.

\section{Funding}

The authors declare that no funding was received for the study.

\section{Availability of data and materials}

Our database contains sensible data which might provide insight in clinical and personnel information about our patients and lead to identification of patients. According to organization restrictions and regulations the data cannot be made public available. Data are however available from the authors upon reasonable request and with permission of the Data Protection Officer at $\mathrm{OUH}$.

\section{Ethics approval and consent to participate}

The database was approved by the OUH - Data Protection Officer (PVO) (approval no 2014/12304).. The present study, which is based on data extracted from this quality database, was approved by OUH-PVO, and consent was waived by our Institutional Review Board (approval no 18/02167).

Consent for publication

Not applicable.

\section{Competing interests}

The authors declare that they have no competing interests.

\section{Author details}

${ }^{1}$ Faculty of Medicine, University of Oslo, Oslo, Norway. ${ }^{2}$ Department of Neurosurgery, Oslo University Hospital, Mailbox 4956, 0424 Oslo, Norway. ${ }^{3}$ Department of Neuroradiology, Oslo University Hospital, Oslo, Norway.

Received: 22 March 2020 Accepted: 28 September 2020

Published online: 14 October 2020

\section{References}

1. Fredø HL, Bakken IJ, Lied B, Rønning P, Helseth E. Incidence of traumatic cervical spine fractures in the Norwegian population: a national registry study. Scand J Trauma Resusc Emerg Med. 2014;22:78 10.1186/s13049-0140078-7.

2. Fredø HL, Rizvi SA, Lied B, Rønning P, Helseth E. The epidemiology of traumatic cervical spine fractures: a prospective population study from Norway. Scand J Trauma Resusc Emerg Med. 2012;20:85. https://doi.org/10. 1186/1757-7241-20-85

3. Robinson AL, Moller A, Robinson Y, Olerud C. C2 fracture subtypes, incidence, and treatment allocation change with age: a retrospective cohort study of 233 consecutive cases. Biomed Res Int. 2017;2017:8321680. https:// doi.org/10.1155/2017/8321680.

4. Pryputniewicz DM, Hadley MN. Axis fractures. Neurosurgery. 2010;66:68-82. https://doi.org/10.1227/01.NEU.0000366118.21964.A8.

5. Anderson LD, D'Alonzo RT. Fractures of the odontoid process of the axis. J Bone Jt Surg Am. 1974;56:1663-74. https://doi.org/10.2106/00004623197456080-00017.

6. Alker GJ, Oh YS, Leslie EV, Lehotay J, Panaro VA, Eschner EG. Postmortem radiology of head neck injuries in fatal traffic accidents. Radiology. 1975;114: 611-7. https://doi.org/10.1148/114.3.611.

7. Bucholz RW, Burkhead WZ, Graham W, Petty C. Occult cervical spine injuries in fatal traffic accidents. J Trauma. 1979:19:768-71. https://doi.org/10.1097/ 00005373-197910000-00009. 
8. Adams VI. Neck injuries: II. Atlantoaxial dislocation--a pathologic study of 14 traffic fatalities. J Forensic Sci. 1992;37:565-73. https://doi.org/10.1520/ JFS13263J.

9. Shears $E$, Armitstead CP. Surgical versus conservative management for odontoid fractures. Cochrane Database Syst Rev. 2008:CD005078. https://doi. org/10.1002/14651858.CD005078.pub2.

10. Robinson $Y$, Robinson A-L, Olerud C. Systematic review on surgical and nonsurgical treatment of type II odontoid fractures in the elderly. Biomed Res Int. 2014;2014:231948. https://doi.org/10.1155/2014/231948.

11. Ryken TC, Hadley MN, Aarabi B, Dhall SS, Gelb DE, Hurlbert RJ, Rozzelle CJ, Theodore N, Walters BC. Management of isolated fractures of the axis in adults. Neurosurgery. 2013;72:132-50. https://doi.org/10.1227/NEU. 0b013e318276ee40.

12. Harrop JS, Hart R, Anderson PA. Optimal treatment for odontoid fractures in the elderly. Spine (Phila Pa 1976). 2010;35:S219-27. https://doi.org/10.1097/ BRS.0b013e3181f32716.

13. Nourbakhsh A, Shi R, Vannemreddy P, Nanda A. Operative versus nonoperative management of acute odontoid type II fractures: a metaanalysis. J Neurosurg Spine. 2009;11:651-8. https://doi.org/10.3171/2009.7. SPINE0991.

14. Rizvi SA, Fredo HL, Lied B, Nakstad PH, Ronning P, Helseth E. Surgical management of acute odontoid fractures: surgery-related complications and long-term outcomes in a consecutive series of 97 patients. J Trauma Acute Care Surg. 2012;72:682-90. https://doi.org/10.1097/TA. 0b013e318236b675.

15. De Bonis $\mathrm{P}$, laccarino C, Musio A, et al. Functional outcome of elderly patients treated for odontoid fracture: a multicenter study. Spine (Phila Pa 1976). 2019;44:951-8. https://doi.org/10.1097/BRS.0000000000002982.

16. Lofrese G, Musio A, De lure F, Cultrera F, Martucci A, laccarino C, Essayed W, Ghadirpour R, Servadei F, Cavallo MA, De Bonis P. Type II odontoid fracture in elderly patients treated conservatively: is fracture healing the goal? Eur Spine J. 2019;28:1064-71. https://doi.org/10.1007/s00586-019-05898-2.

17. Patel A, Zakaria R, Al-Mahfoudh R, Clark S, Barrett C, Sarsam Z, Pillay R, Pigott TD, Wilby MJ. Conservative management of type II and III odontoid fractures in the elderly at a regional spine Centre: a prospective and retrospective cohort study. Br J Neurosurg. 2015;29:249-53. https://doi.org/ 10.3109/02688697.2014.958055.

18. Iyer S, Hurlbert RJ, Albert TJ. Management of odontoid fractures in the elderly: a review of the literature and an evidence-based treatment algorithm. Neurosurgery. 2018;82:419-30. https://doi.org/10.1093/neuros/ nyx546.

19. Bajada S, Ved A, Dudhniwala AG, Ahuja S. Predictors of mortality following conservatively managed fractures of the odontoid in elderly patients. Bone Jt J. 2017;99-B:116-21. https://doi.org/10.1302/0301-620X.99B1.37989.

20. Venkatesan M, Northover JR, Wild JB, Johnson N, Lee K, Uzoigwe CE, Braybrooke JR. Survival analysis of elderly patients with a fracture of the odontoid peg. Bone Jt J. 2014;96-B:88-93. https://doi.org/10.1302/0301620X.96B1.32024.

21. Wagner SC, Schroeder GD, Kepler CK, Schupper AJ, Kandziora F, Vialle EN, Oner C, Fehlings MG, Vaccaro AR. Controversies in the management of geriatric odontoid fractures. J Orthop Trauma. 2017;31:S44-8. https://doi. org/10.1097/BOT.0000000000000948.

22. Statistisk Sentralbyrå (2019) Statistics Norway. SSE, Norway https://www.ssb. no/befolkning/faktaside/befolkningen. Access date February 2, 2020.

23. American Society Anestesiologists (2014) ASA physical status classification system. https://www.asahq.org/standards-and-guidelines/asa-physical-statusclassification-system. Access date February 2, 2020.

24. Grauer JN, Shafi B, Hilibrand AS, Harrop JS, Kwon BK, Beiner JM, Albert TJ, Fehlings MG, Vaccaro AR. Proposal of a modified, treatment-oriented classification of odontoid fractures. Spine J. 2005;5:123-9. https://doi.org/10. 1016/j.spinee.2004.09.014

25. Stein SC, Spettell C. The head injury severity scale (HISS): a practical classification of closed-head injury. Brain Inj. 1995;9:437-44. https://doi.org/ 10.3109/02699059509008203.

26. World Health Organization. ICD-10: international statistical classification of diseases and related health problems. Geneva: World Health Organization; 2009.

27. Robinson AL, Olerud C, Robinson Y. Epidemiology of C2 fractures in the 21st century: a national registry cohort study of 6,370 patients from 1997 to 2014. Adv Orthop. 2017;2017:6516893. https://doi.org/10.1155/2017/ 6516893.
28. Daniels AH, Arthur M, Esmende SM, Vigneswaran H, Palumbo MA. Incidence and cost of treating axis fractures in the United States from 2000 to 2010. Spine (Phila Pa 1976). 2014;39:1498-505. https://doi.org/10.1097/BRS. 0000000000000417.

29. Smith HE, Kerr SM, Fehlings MG, Chapman J, Maltenfort M, Zavlasky J, Harris E, Albert TJ, Harrop J, Hilibrand AS, Anderson DG, Vaccaro AR. Trends in epidemiology and management of type II odontoid fractures: 20-year experience at a model system spine injury tertiary referral center. J Spinal Disord Tech. 2010;23:501-5. https://doi.org/10.1097/BSD.0b013e3181cc43c7.

30. Zusman NL, Ching AC, Hart RA, Yoo JU. Incidence of second cervical vertebral fractures far surpassed the rate predicted by the changing age distribution and growth among elderly persons in the United States (20052008). Spine (Phila Pa 1976). 2013;38:752-6. https://doi.org/10.1097/BRS. Ob013e31827ab62a.

31. Radovanovic I, Urquhart JC, Rasoulinejad P, Gurr KR, Siddiqi F, Bailey CS. Patterns of C-2 fracture in the elderly: comparison of etiology, treatment, and mortality among specific fracture types. J Neurosurg Spine. 2017;27: 494-500. https://doi.org/10.3171/2017.3.SPINE161176.

32. Bednar DA, Parikh J, Hummel J. Management of type II odontoid process fractures in geriatric patients; a prospective study of sequential cohorts with attention to survivorship. J Spinal Disord. 1995;8:166-9. https://doi.org/10. 1097/00002517-199504000-00013.

33. Hanigan WC, Powell FC, Elwood PW, Henderson JP. Odontoid fractures in elderly patients. J Neurosurg. 1993;78:32-5. https://doi.org/10.3171/jns.1993. 78.1.0032.

34. Malik SA, Murphy M, Connolly P, O'Byrne J. Evaluation of morbidity, mortality and outcome following cervical spine injuries in elderly patients. Eur Spine J. 2008;17:585-91. https://doi.org/10.1007/s00586-008-0603-3.

35. Muller EJ, Wick M, Russe O, Muhr G. Management of odontoid fractures in the elderly. Eur Spine J. 1999;8:360-5. https://doi.org/10.1007/ s005860050188.

36. Pepin JW, Bourne RB, Hawkins RJ. Odontoid fractures, with special reference to the elderly patient. Clin Orthop Relat Res. 1985:178-83. https://doi.org/10. 1097/00003086-198503000-00025.

37. Schoenfeld AJ, Bono CM, Reichmann WM, Warholic N, Wood KB, Losina E, Katz JN, Harris MB. Type II odontoid fractures of the cervical spine: do treatment type and medical comorbidities affect mortality in elderly patients? Spine (Phila Pa 1976). 2011;36:879-85. https://doi.org/10.1097/BRS. 0b013e3181e8e77c

38. Tricco AC, Thomas SM, Veroniki AA, et al. Comparisons of interventions for preventing falls in older adults: a systematic review and meta-analysis. JAMA. 2017;318:1687-99. https://doi.org/10.1001/jama.2017.15006.

39. Just KS, Schneider KL, Schurig M, Stingl JC, Brockmoller J. Falls: the adverse drug reaction of the elderly and the impact of pharmacogenetics. Pharmacogenomics. 2017;18:1281-97. https://doi.org/10.2217/pgs-2017-0018.

40. Todd C, Skelton D. What are the main risk factors for falls among older people and what are the most effective interventions to prevent these falls? Copenhagen: WHO Regional Office for Europe; 2004. http://www.euro.who. int/document/E82552.pdf. Accessed 05 April 2004.

41. Koech F, Ackland HM, Varma DK, Williamson OD, Malham GM. Nonoperative management of type II odontoid fractures in the elderly. Spine (Phila Pa 1976). 2008;33:2881-6. https://doi.org/10.1097/BRS.0b013e31818d5407.

42. Graffeo CS, Perry A, Puffer RC, Carlstrom LP, Chang W, Mallory GW, Clarke MJ. Deadly falls: operative versus nonoperative management of type II odontoid process fracture in octogenarians. J Neurosurg Spine. 2017;26:4-9. https://doi.org/10.3171/2016.3.SPINE151202.

43. Chapman J, Smith JS, Kopjar B, Vaccaro AR, Arnold P, Shaffrey Cl, Fehlings MG. The AOSpine North America geriatric odontoid fracture mortality study: a retrospective review of mortality outcomes for operative versus nonoperative treatment of 322 patients with long-term follow-up. Spine (Phila Pa 1976). 2013;38:1098-104. https://doi.org/10.1097/BRS. Ob013e318286f0cf.

44. Alas H, Segreto FA, Chan HY, Brown AE, Pierce KE, Bortz CA, Horn SR, Varlotta CG, Baker JF, Passias PG. Association between frailty status and odontoid fractures after traumatic falls: investigation of varying injury mechanisms among 70 elderly odontoid fracture patients. J Orthop Trauma. 2019;33:e484-8. https://doi.org/10.1097/BOT.0000000000001597.

45. Lomoschitz FM, Blackmore CC, Stadler A, Linnau KF, Mann FA. Fractures of the atlantoaxial complex in the elderly: assessment of radiological spectrum of fractures and factors influencing imaging diagnosis. Rofo. 2004;176:222-8. https://doi.org/10.1055/s-2004-817630. 
46. Majercik S, Tashjian RZ, Biffl WL, Harrington DT, Cioffi WG. Halo vest immobilization in the elderly: a death sentence? J Trauma. 2005:59:350-6; discussion 356-358. https://doi.org/10.1097/01.ta.0000174671.07664.7c.

47. Tadros A, Sharon M, Craig K, Krantz W. Characteristics and management of emergency department patients presenting with C2 cervical spine fractures. Biomed Res Int. 2019;2019:4301051. https://doi.org/10.1155/2019/4301051.

48. Hadley MN, Browner C, Sonntag VK. Axis fractures: a comprehensive review of management and treatment in 107 cases. Neurosurgery. 1985;17:281-90. https://doi.org/10.1227/00006123-198508000-00006.

49. Joestl J, Lang NW, Tiefenboeck TM, Hajdu S, Platzer P. Management and outcome of dens fracture nonunions in geriatric patients. J Bone Jt Surg Am. 2016;98:193-8. https://doi.org/10.2106/JBJS.0.00101.

50. Muller EJ, Schwinnen I, Fischer K, Wick M, Muhr G. Non-rigid immobilisation of odontoid fractures. Eur Spine J. 2003;12:522-5. https://doi.org/10.1007/ s00586-003-0531-1.

51. Ryan MD, Taylor TK. Odontoid fractures in the elderly. J Spinal Disord. 1993; 6:397-401. https://doi.org/10.1097/00002517-199306050-00005.

52. Seybold EA, Bayley JC. Functional outcome of surgically and conservatively managed dens fractures. Spine (Phila Pa 1976). 1998;23:1837-45; discussion 1845-1836. https://doi.org/10.1097/00007632-199809010-00006.

53. Wagar M, Van-Popta D, Barone DG, Sarsam Z. External immobilization of odontoid fractures: a systematic review to compare the halo and hard collar. World Neurosurg. 2017;97:513-7. https://doi.org/10.1016/j.wneu.2016. 10.035.

54. Dhall SS, Yue JK, Winkler EA, Mummaneni PV, Manley GT, Tarapore PE. Morbidity and mortality associated with surgery of traumatic C2 fractures in octogenarians. Neurosurgery. 2017;80:854-62. https://doi.org/10.1093/ neuros/nyw168.

55. Pearson AM, Martin BI, Lindsey M, Mirza SK. C2 vertebral fractures in the medicare population: incidence, outcomes, and costs. J Bone Jt Surg Am. 2016;98:449-56. https://doi.org/10.2106/JBJS.0.00468.

\section{Publisher's Note}

Springer Nature remains neutral with regard to jurisdictional claims in published maps and institutional affiliations.

Ready to submit your research? Choose BMC and benefit from:

- fast, convenient online submission

- thorough peer review by experienced researchers in your field

- rapid publication on acceptance

- support for research data, including large and complex data types

- gold Open Access which fosters wider collaboration and increased citations

- maximum visibility for your research: over $100 \mathrm{M}$ website views per year

At $\mathrm{BMC}$, research is always in progress.

Learn more biomedcentral.com/submissions 